\title{
Efficiency Optimization in Burst-Mode Buck DC/DC Converters for Sensor Nodes
}

\author{
Ferran Reverter, Chris Glaser, and Manel Gasulla
}

\begin{abstract}
In autonomous sensor nodes, switching dc/dc converters are usually employed to power the sensor electronics and also to maintain the operating voltage of an energy transducer around its maximum power point. In such a context, this paper optimizes the power efficiency of buck dc/dc converters when operating in burst mode, which is preferable than the conventional pulse-width modulation technique in lowpower sensor applications. The optimization is carried out by selecting an optimal inductor current to efficiently transfer the energy from the input to the output during the burst. Such optimization is applied when regulating the converter's output voltage, which corresponds to the supply voltage of the sensor electronics, and also the input voltage, which corresponds to the operating voltage of the energy transducer that is here a photovoltaic module. The theoretical analysis and the experimental results reported herein prove the existence of such an optimal inductor current in both scenarios. Experimental tests with a commercial buck de/dc converter (TPS62750) show that the use of this optimal inductor current provides up to $9 \%$ increase in efficiency, thus prolonging the operating lifetime of the sensor node.
\end{abstract}

Index Terms-Autonomous sensor, buck converter, burst mode, dc/dc converter, efficiency, energy harvester, light-load conditions, operating lifetime, photovoltaic module, sensor node.

\section{INTRODUCTION}

$I^{1}$ $\mathrm{N}$ the society of the $21^{\text {st }}$ century, almost everything is getting smart thanks to the proliferation of information and communication technology and, in particular, to the deployment of technologies such as wireless sensor networks and the internet of things. In this context, sensor nodes play an essential role to monitor what is happening in and/or around the smart thing. From the point of view of the power system, a sensor node (with sensing elements, read-out electronics, a digital processor, and a transceiver [1]) is usually seen as a light load since its current consumption is low, for instance: units or tens of $\mathrm{mA}$ when the node is awake and a few $\mu \mathrm{A}$ when asleep. The power processing circuit of a sensor node generally relies on either a buck [2] or a boost [3] switching

This work was supported by the Spanish Ministry of Economy and Competitiveness and the European Regional Development Fund under project TEC2016-76991-P

F. Reverter and M. Gasulla are with the e-CAT Research Group, Department of Electronic Engineering, Universitat Politècnica de Catalunya (UPC) - BarcelonaTech, C/ Esteve Terradas 7, Castelldefels 08860, Spain (email: ferran.reverter@upc.edu; manel.gasulla@upc.edu).

C. Glaser is with Texas Instruments, 12500 TI Blvd, Dallas (TX) 75243, USA (e-mail: c-glaser@ti.com). $\mathrm{dc} / \mathrm{dc}$ converter, which is placed between the energy source (e.g. a battery) and the sensor electronics to provide a stable output voltage and efficiently transfer the energy from the battery to the electronics. However, the efficiency of a switching dc/dc converter operating in a conventional pulsewidth modulation (PWM) is not as good as expected under light-load conditions [4]. This is because PWM involves a fixed switching frequency that generates significant switching losses. To cope with this limitation, the dc/dc converter can operate in a variable-frequency mode such as pulse-frequency modulation (PFM) [5] or burst mode (BM) [6], [7]. In PFM, the switching frequency is scaled down with the load current, whereas in BM, the converter operates in PWM sporadically, thus resulting in a burst of energy pulses transferred to the output. BM has the advantage, in comparison with PFM, that the core of the circuit controlling the power transistors is the same as in a conventional PWM converter.

Techniques for improving the efficiency of PWM converters without perturbing the switching frequency have also been proposed, for instance: 1) dynamic adjustment of the gate-driving voltage of the power transistors [8], where the gate-driving voltage decreases with decreasing the load current, thus providing a 5\% increase in efficiency at light loads. Its main drawback is the layout area required by the generator of the gate-driving voltages, which is almost a third of the overall chip area. 2) Charge-recycling technique [9], where part of the energy stored at the gate of the power transistors is transferred to the output, thus reducing losses due to the charge-discharge process of the gate capacitances. The efficiency improvement at light loads was around 1-2\%. 3) Dynamic adjustment of the active size of the power transistors [10], [11], where the size of the transistors decreases with decreasing the load current, providing up to $7 \%$ increase in efficiency [11]. 4) Soft-switching techniques, which eliminate the voltage-current overlap losses with an efficiency improvement of 5\% [12] and 12\% [13]. The last two methods, however, were proposed for load currents higher than 50 (or 100) $\mathrm{mA}$, which is a high value for low-power sensor nodes.

If the sensor node harvests energy from the environment, another switching $\mathrm{dc} / \mathrm{dc}$ converter is necessary to regulate the operating voltage of the energy transducer, which is a photovoltaic (PV) module in the present study. This converter is now placed between the energy transducer and a storage unit (e.g. a rechargeable battery) so as to maintain the operating voltage of the energy transducer around its maximum power point (MPP) and to transfer the energy from 


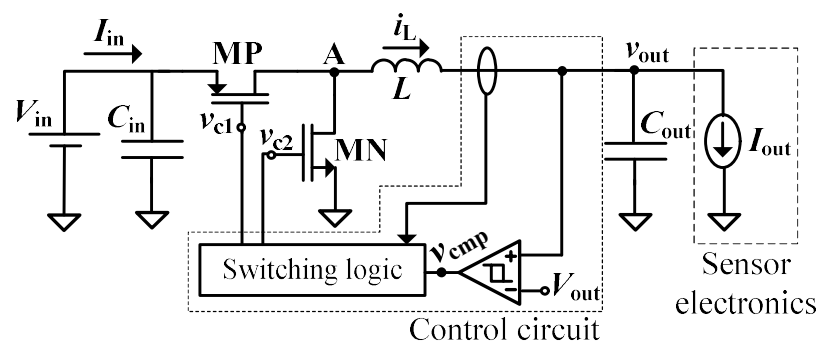

(a)

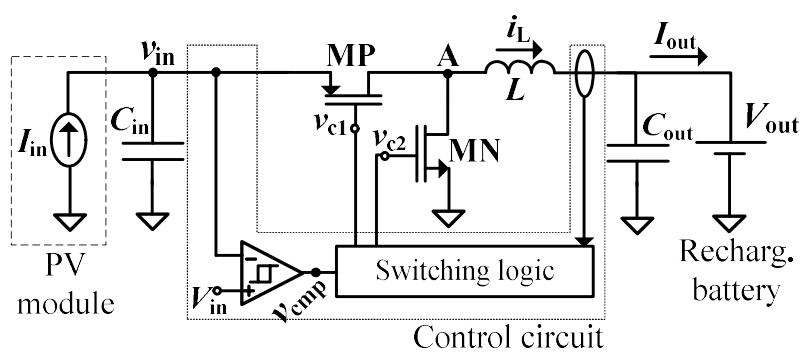

(b)

Fig. 1. Schematic of a synchronous buck dc/dc converter operating in BM when regulating (a) the output voltage, and (b) the input voltage.

the transducer to the storage unit in an efficient way [14],[15]. Therefore, unlike what has been discussed before, the converter here regulates its input voltage. In this scenario, PWM converters are not recommended either, especially for subwatt energy transducers. Control strategies based on PFM [16] and BM [17]-[19] are again preferable to reduce the switching losses and, hence, increase the efficiency. Taking into account the previous discussion, the overall power system of an energy-efficient sensor node can require [20]: 1) a first $\mathrm{dc} / \mathrm{dc}$ converter regulating the input voltage (i.e. the operating voltage of the energy transducer) and transferring energy to a storage unit, and 2) a second $\mathrm{dc} / \mathrm{dc}$ converter regulating the output voltage (i.e. the supply voltage of the sensor electronics) and transferring energy from the storage unit.

The control strategies explained before have parameters that can be optimized to improve the converter efficiency, for example: an optimal gate-driving voltage [8] and an optimal size of the power transistors [11] in PWM, an optimal on-time or peak current in PFM [21], and an optimal inductor current in BM. The latter was studied for a boost topology when regulating the output [7] and the input [19] voltage. It was proved that there is an optimal inductor current to transfer the energy from the battery to the electronics (or from the transducer to the storage unit) during the burst. An appropriate selection of this current provided up to $10 \%$ increase in efficiency, which involves the following benefits: a longer battery lifetime, an increment of the available harvested energy, and/or a smaller energy transducer (e.g. a PV module with a smaller area).

Following the approach developed in [7] and [19], this paper optimizes the efficiency of a buck, instead of a boost, $\mathrm{dc} / \mathrm{dc}$ converter operating in BM for both scenarios: input and output voltage regulation. Moreover, unlike [7] and [19], the model is extended considering that the quiescent current depends on the operating conditions of the converter. This analysis of the buck converter is of interest for prolonging the autonomy of low-power sensor nodes in which the supply voltage of the sensor electronics is lower than the storage-unit voltage and/or the operating voltage of the $\mathrm{PV}$ module is higher than the storage-unit voltage. This paper also aims to compare the performance of buck and boost topologies operating in BM. Although the expressions of efficiency and optimal inductor current are not the same for both topologies, these can be uniformly written through a more general approach proposed at the end of this paper.

The paper is organized as follows. Section II qualitatively describes the operating principle of a buck converter in BM applied to low-power sensor nodes. Section III theoretically analyzes its power efficiency and the resulting optimal inductor current. Section IV describes the materials and method employed to prove the concepts evaluated in Section III. Section V shows the experimental results considering that the buck converter is connected to either low-power sensor electronics or a low-power PV module. Section VI compares the performance of buck and boost converters and then provides general expressions applicable to both topologies. Finally, Section VII draws the main conclusions. In all sections, both scenarios (i.e. input and output voltage regulation) are considered.

\section{OPERATING PRINCIPLE}

Let us assume a sensor node harvesting energy from the environment. The regulation of the supply voltage of the sensor electronics and of the operating voltage of the PV module is proposed to be carried out through the circuits shown in Figs. 1(a) and 1(b), respectively. In both cases, the power processing circuit relies on a synchronous buck $\mathrm{dc} / \mathrm{dc}$ converter operating in BM since both the sensor electronics and the PV module are considered of low power. The converter has an inductor $(L)$ and two power MOSFET transistors (MP and $\mathrm{MN}$ ) with the corresponding gate signals $\left(v_{\mathrm{c} 1}\right.$ and $\left.v_{\mathrm{c} 2}\right)$ generated by a control circuit [19].

In Fig. 1(a), the input of the converter is connected to a battery modeled by a dc voltage source $\left(V_{\text {in }}\right)$, and the output to the sensor electronics with a de current consumption of $I_{\text {out }}$ and a dc operating voltage of $V_{\text {out }}$. On the other hand, in Fig. 1(b), the input is connected to a PV module modeled by a dc current source $\left(I_{\text {in }}\right)$, and the output to a rechargeable battery modeled by a dc voltage source $\left(V_{\text {out }}\right)$. The PV module operates around a dc voltage $\left(V_{\text {in }}\right)$ provided by an MPP tracking controller, which is out of the scope of this work and can be found elsewhere [15-18], [22]. In Fig. 1(a), the independent input/output variables of the converter are $V_{\text {in }}$, $V_{\text {out, }}$ and $I_{\text {out }}$, whereas in Fig. $1(\mathrm{~b})$, these are $V_{\text {in }}, I_{\text {in }}$, and $V_{\text {out }}$. The dependent variable is $I_{\text {in }}=V_{\text {out }} I_{\text {out }} / V_{\text {in }}$ in Fig. 1(a) and $I_{\text {out }}=V_{\text {in }} I_{\text {in }} / V_{\text {out }}$ in Fig. 1(b), assuming no losses. At both input and output, there is a capacitor in parallel $\left(C_{\text {in }}\right.$ and $C_{\text {out }}$, respectively). 


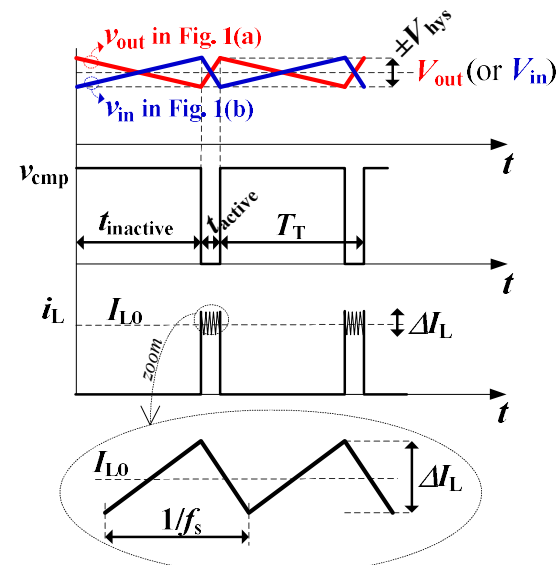

Fig. 2. Waveforms of interest from the circuits in Fig. 1 operating in BMCCM.

Fig. 2 shows, in red (blue) color, the regulation of $v_{\text {out }}\left(v_{\text {in }}\right)$ around $V_{\text {out }}\left(V_{\text {in }}\right)$ in Fig. 1(a) [Fig. 1(b)] when operating in BM. This involves two stages: inactive and active, which last $t_{\text {inactive }}$ and $t_{\text {active, }}$ respectively, where $t_{\text {inactive }}<<t_{\text {active }}$ so as to reduce the power losses. In inactive mode, the converter is deactivated and $I_{\text {out }}$ discharges $C_{\text {out }}\left(I_{\text {in }}\right.$ charges $\left.C_{\text {in }}\right)$, thus decreasing $v_{\text {out }}$ (increasing $v_{\text {in }}$ ). When $v_{\text {out }}=V_{\text {out }}-V_{\text {hys }}$ $\left(v_{\text {in }}=V_{\text {in }}+V_{\text {hys }}\right)$, where $V_{\text {hys }}$ is the hysteresis of the comparator of the control circuit, the state of the comparator output $\left(v_{\mathrm{cmp}}\right)$ changes and the active mode starts. Then, the converter operates in PWM [23] transferring energy from the input to the output in a burst, thus increasing $v_{\text {out }}$ (decreasing $v_{\text {in }}$ ). A current-programmed mode control in continuous conduction mode $(\mathrm{CCM})$ is considered so that the inductor current $\left(i_{\mathrm{L}}\right)$ has an average of $I_{\mathrm{L} 0}$ and a ripple of $\Delta I_{\mathrm{L}}$. Once $i_{\mathrm{L}}$ is well regulated around $I_{\mathrm{L} 0}$, the duty cycle of the PWM signal is [23]

$$
D=\frac{V_{\text {out }}}{\eta V_{\text {in }}}
$$

where $\eta$ is the power efficiency of the converter. When $v_{\text {out }}=V_{\text {out }}+V_{\text {hys }}\left(v_{\text {in }}=V_{\text {in }}-V_{\text {hys }}\right)$, the converter is deactivated and the process starts again.

According to the previous operating principle, the charge extracted from $C_{\text {out }}$ in Fig. 1(a) [accumulated in $C_{\text {in }}$ in Fig. 1(b)] in inactive mode equals that accumulated in $C_{\text {out }}$ (extracted from $C_{\text {in }}$ ) in active mode. This can be written, respectively, as

$$
\begin{aligned}
& I_{\text {out }} t_{\text {inactive }}=\left(I_{\mathrm{L} 0}-I_{\text {out }}\right) t_{\text {active }} \\
& I_{\text {in }} t_{\text {inactive }}=\left(I_{\mathrm{L} 0} D-I_{\text {in }}\right) t_{\text {active }}
\end{aligned}
$$

From (2) and (3), the overall duty cycle (i.e. $D_{\mathrm{T}}=t_{\text {active }} / T_{\mathrm{T}}$, where $T_{\mathrm{T}}=t_{\text {inactive }}+t_{\text {active }}$ ) can be equivalently expressed for the circuits in Figs. 1(a) and (b) as, respectively,

$$
\begin{gathered}
D_{\mathrm{T}}=\frac{I_{\text {out }}}{I_{\mathrm{L} 0}} \\
D_{\mathrm{T}}=\frac{\eta V_{\text {in }} I_{\text {in }}}{V_{\text {out }} I_{\mathrm{L} 0}}
\end{gathered}
$$

which show that the lower $I_{\text {out }}$ or $I_{\text {in }}$, the lower $D_{\mathrm{T}}$ and, hence, the lower the equivalent switching frequency (i.e. $f_{\mathrm{s}} \cdot D_{\mathrm{T}}$ ), thus reducing the effects of switching losses on the efficiency.

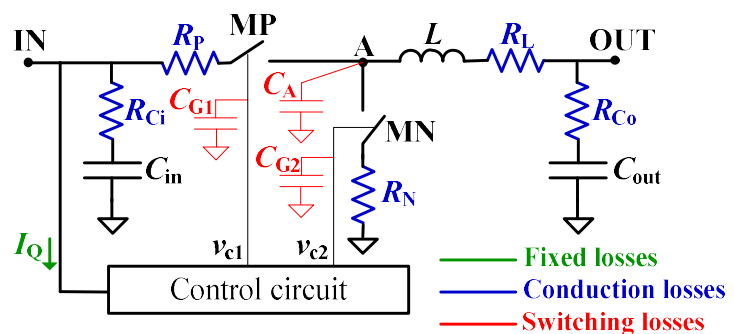

Fig. 3. Equivalent circuit model for the analysis of power losses in the circuits shown in Fig. 1.

\section{THEORETICAL ANALYSIS}

In order to analyze the power efficiency of the circuits shown in Fig. 1, we propose to use the equivalent circuit model represented in Fig. 3, which includes: the parasitic resistance $\left(R_{\mathrm{Ci}}, R_{\mathrm{P}}, R_{\mathrm{N}}, R_{\mathrm{L}}\right.$, and $\left.R_{\mathrm{Co}}\right)$ of the main components ( $C_{\mathrm{in}}, \mathrm{MP}, \mathrm{MN}, L$, and $C_{\text {out }}$, respectively), and the parasitic capacitance $\left(C_{\mathrm{A}}, C_{\mathrm{G} 1}\right.$, and $\left.C_{\mathrm{G} 2}\right)$ of the main nodes (node $\mathrm{A}$, gate of MP and MN, respectively). The control circuit is assumed to be powered from the input, as usually happens in buck converters, with a current consumption of $I_{\mathrm{Q}}$.

Three types of power losses are involved in the circuit shown in Fig. 3 [7]: fixed, conduction, and switching losses. Their expression in both active and inactive modes is summarized in Table I, where $f_{\mathrm{s}}$ is the switching frequency, and $t_{\mathrm{c}}$ is the average transition time of MP when switching from on to off and vice versa. The overall power losses in active and inactive modes ( $P_{\mathrm{L}, \text { active }}$ and $P_{\mathrm{L} \text {,inactive, respectively) }}$ can be calculated by adding the three components in Table I, and the average power losses over $T_{\mathrm{T}}$ can be expressed and approximated (assuming $P_{\mathrm{L} \text {,active }} \gg P_{\mathrm{L} \text {,inactive) }}$ as

$$
\begin{aligned}
& P_{\mathrm{L}}=P_{\mathrm{L} \text {,active }} D_{\mathrm{T}}+P_{\mathrm{L} \text {,inactive }}\left(1-D_{\mathrm{T}}\right) \\
& =\left(P_{\mathrm{L} \text {,active }}-P_{\mathrm{L} \text {,inactive }}\right) D_{\mathrm{T}}+P_{\mathrm{L} \text {,inactive }} \approx P_{\mathrm{L} \text {,active }} D_{\mathrm{T}}+P_{\mathrm{L} \text {,inactive }}
\end{aligned}
$$

where $D_{\mathrm{T}}$ is defined by either (4) or (5). Then, the efficiency of the converter can be estimated as

$$
\eta=1-\frac{P_{\mathrm{L}}}{P_{\text {in }}}=\left(1+\frac{P_{\mathrm{L}}}{P_{\text {out }}}\right)^{-1}
$$

where $P_{\text {out }}$ is the output power (i.e. $V_{\text {out }} I_{\text {out }}$ ) delivered to the sensor electronics in Fig. 1(a), and $P_{\text {in }}$ is the input power (i.e. $\left.V_{\text {in }} I_{\text {in }}\right)$ provided by the PV module in Fig. 1(b).

\section{A. Basic model}

For both scenarios of regulation, the efficiency resulting from (7) can be written in a first-order approximation as

$$
\eta \approx\left\{\begin{array}{l}
1-\frac{P_{\mathrm{L}}}{P_{\text {out }}} \text { in Fig. 1(a) } \\
1-\frac{P_{\mathrm{L}}^{\prime}}{P_{\text {in }}} \text { in Fig. 1(b) }
\end{array}\right\}=1-\frac{\alpha_{i}}{I_{\mathrm{L} 0}}-\beta_{i} I_{\mathrm{L} 0}-\gamma_{i}
$$

where $P_{\mathrm{L}}^{\prime}$ is the average power losses resulting from (6) assuming $\eta=1$ in (5), and the coefficients $\alpha_{i}, \beta_{i}$, and $\gamma_{i}$ with $i=1$ are specified in Table II; note that two equivalent expressions are given for $\gamma_{1}$ as a function of the independent 
TABLE I

POWER LOSS COMPONENTS OF THE CIRCUIT IN FIG. 3

\begin{tabular}{|c|c|c|}
\hline Power losses & Active mode & Inactive mode \\
\hline Fixed & $V_{\text {in }} I_{\mathrm{Q}}$ & $V_{\text {in }} I_{\mathrm{Q}}$ \\
\hline Conduction & $\begin{array}{c}R_{\mathrm{eq}, \mathrm{a}} I_{\mathrm{L} 0}^{2}{ }^{(\mathrm{a})}, \text { where } \\
R_{\mathrm{eq}, \mathrm{a}}{ }^{(\mathrm{b})}=\left(R_{\mathrm{Ci}}+R_{\mathrm{P}}\right) D+ \\
R_{\mathrm{N}}(1-D)+R_{\mathrm{L}}+R_{\mathrm{Co}}\end{array}$ & $R_{\mathrm{Ci}} I_{\text {in }}^{2}+R_{\mathrm{Co}} I_{\text {out }}^{2}$ \\
\hline Switching & $\begin{array}{c}f_{\mathrm{s}}\left(C_{\mathrm{eq}} V_{\mathrm{in}}^{2}+V_{\mathrm{in}} I_{\mathrm{L} 0} t_{\mathrm{c}}\right), \text { where } \\
C_{\mathrm{eq}}=C_{\mathrm{G} 1}+C_{\mathrm{G} 2}+C_{\mathrm{A}} \text { (c) }\end{array}$ & 0 \\
\hline
\end{tabular}

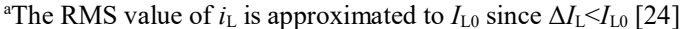

${ }^{\mathrm{b}}$ If $I_{\mathrm{L} 0} \gg\left(I_{\mathrm{in}}, I_{\mathrm{out}}\right), R_{\mathrm{Ci}}\left(\right.$ or $\left.R_{\mathrm{Co}}\right)$ can be considered in series with $R_{\mathrm{p}}\left(\right.$ or $\left.R_{\mathrm{L}}\right)$.

${ }^{\mathrm{c}}$ The three capacitances have the same charging voltage (i.e. $V_{\text {in }}$ ) since the

control circuit is powered from the input.

variables for each case of regulation. According to (8) and Table II, the lower $V_{\text {in }}$ and/or the higher $V_{\text {out }}$, the higher $\eta$. The effect of $I_{\text {out }}$ in Fig. 1(a) [or $I_{\text {in }}$ in Fig. 1(b)] on $\eta$ depends on which of the last two terms of $\gamma_{1}$ dominates.

The value of $I_{\mathrm{L} 0}$ selected to transfer the energy from the input to the output during the burst plays an important role in the efficiency of the converter, as shown in (8). There is an optimal value of $I_{\mathrm{L} 0}$ leading to maximum efficiency that can be calculated by equating $\partial \eta / \partial I_{\mathrm{L} 0}$ to zero, thus resulting in

$$
I_{\mathrm{L} 0, \text { opt }}=\sqrt{\frac{V_{\text {in }} I_{\mathrm{Q}}+C_{\text {eq }} V_{\text {in }}^{2} f_{\mathrm{s}}}{R_{\text {eq,a }}+\varphi}}
$$

where $\varphi$ is a correction factor equal to zero in this basic model. According to (9), $I_{\mathrm{L} 0 \text {,opt }}$ depends on $V_{\text {in }}$ that is the battery voltage in Fig. 1(a) and the operating voltage of the PV module in Fig. 1(b).

\section{B. Advanced model}

In Section III.A, $I_{\mathrm{Q}}$ is assumed constant and independent of the operating conditions of the converter. This consideration, however, is not valid for the commercial buck converter tested in Section V. Actually, $I_{\mathrm{Q}}$ linearly depends on the selected value of $I_{\mathrm{L} 0}$ as follows

$$
I_{\mathrm{Q}}=I_{\mathrm{Q} 0}\left(1+k I_{\mathrm{L} 0}\right)
$$

where $I_{\mathrm{Q} 0}$ is the value of $I_{\mathrm{Q}}$ when $I_{\mathrm{L} 0}=0$, and $k$ is a positive proportionality constant.

If the analysis in Section III.A is applied again but considering (10), then $\eta$ can also be written by (8) but assuming the coefficients with $i=2$ in Table II. The additional term of $\beta_{2}$ leads to an increase of $\eta$ with increasing $I_{\text {out }}\left(I_{\text {in }}\right)$ in Fig. 1(a) [Fig. 1(b)]. Moreover, $I_{\mathrm{L} 0 \text {,opt }}$ can also be expressed by (9) but replacing $I_{\mathrm{Q}}$ by $I_{\mathrm{Q} 0}$ and assuming $\varphi=k I_{\mathrm{Q} 0} V_{\text {in }} / I_{\text {out }}$ $\left(=k I_{\mathrm{Q} 0} V_{\text {out }} / I_{\text {in }}\right)$ in Fig. 1(a) [Fig. 1(b)].

\section{MATERIALS AND METHOD}

The circuits in Figs. 1(a) and (b) have been tested

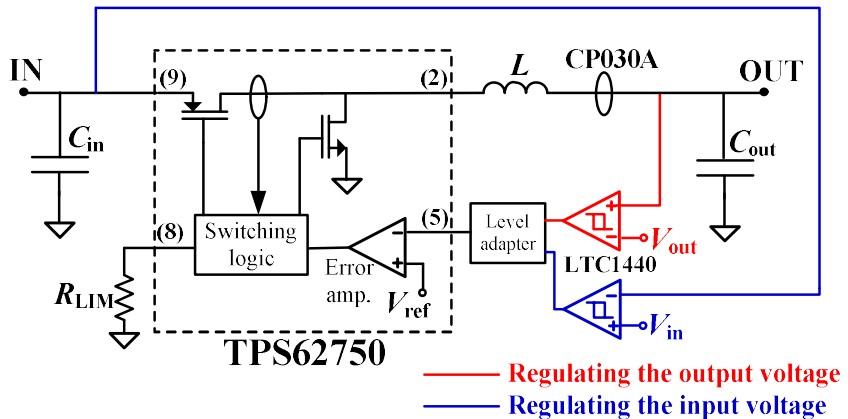

Fig. 4. Application circuit based on the TPS62750 employed to prove the concept of optimal inductor current; the numbers given in brackets are the pin numbers of the TPS62750.

experimentally in two different printed circuit boards using a commercial buck dc/dc converter (TPS62750 from Texas Instruments [25]) with $f_{\mathrm{s}}=2.25 \mathrm{MHz}$ and a control circuit powered from the input. In this converter, the average input current (and, hence, indirectly $I_{\mathrm{L} 0}$ ) can be adjusted through an external resistor $\left(R_{\mathrm{LIM}}\right)$. The actual value of $I_{\mathrm{L} 0}$ was monitored for each test condition by a clamp-on current probe (CP030A) connected to a digital oscilloscope (Lecroy Wave Surfer 3024).

In order to have the BM operation shown in Fig. 2, an external ultralow-power comparator (LTC1440 from Linear Technology) with an adjustable hysteresis was placed before the feedback (FB) input of the buck converter (pin \#5), as shown in Fig. 4. Moreover, a resistor-based level adapter was placed between the LTC1440 output and the FB input so that the internal error amplifier (with a reference voltage, $V_{\text {ref, }}$ of $600 \mathrm{mV}$ ) operated close to its typical operating point. To be precise: a high level of the LTC1440 output was converted to $700 \mathrm{mV}$ stopping the TPS62750, whereas a low level was converted to $300 \mathrm{mV}$ moving the TPS62750 into active mode.

The operating conditions, instrumentation, and components to test the circuits in Figs. 1(a) and 1(b) are summarized in Tables III and IV, respectively. The values of $V_{\text {out }}$ and $I_{\text {out }}$ in Fig. 1(a) were selected considering that the converter is intended to power an awake sensor node with low-voltage electronics and an average current consumption in the $\mathrm{mA}$ range. On the other hand, the values of $V_{\text {in }}$ and $I_{\text {in }}$ in Fig. 1(b) were selected using as a reference the typical MPP voltage and current of the commercial PV module tested later. When regulating the output (input) voltage, the output (input) power was calculated as $V_{\text {out }} I_{\text {out }}\left(V_{\text {in }} I_{\text {in }}\right)$, whereas the average input (output) power was measured by a power analyzer (Yokogawa WT310) with a sampling frequency of $100 \mathrm{kSa} / \mathrm{s}$ and an update rate of $5 \mathrm{~s}$.

The circuit in Fig. 1(b) was also applied to regulate the operating voltage of a commercial ultra-thin low-power PV module (SP4.2-37 from PowerFilm) suitable for low-power autonomous sensor nodes. Its datasheet specifies a typical MPP current/voltage/power of $22 \mathrm{~mA} / 4.2 \mathrm{~V} / 92 \mathrm{~mW}$ at standard test conditions (STC) (i.e. a solar irradiance of $1000 \mathrm{~W} / \mathrm{m}^{2}$ with AM1.5 and a cell temperature of $25^{\circ} \mathrm{C}$ ). Two tests were carried out: 
TABLE II

EXPRESSION FOR THE COEFFICIENTS $\alpha, \beta$, AND $\gamma$ TO BE APPLIED IN (8)

\begin{tabular}{|c|c|c|c|c|}
\hline & & $i=1($ basic model $)$ & $i=2($ advanced model $)$ & $i=3$ (basic uniform model) \\
\hline$\alpha_{i}$ & & $\left(V_{\text {in }} I_{\mathrm{Q}}+C_{\text {eq }} V_{\text {in }}^{2} f_{\mathrm{s}}\right) / V_{\text {out }}$ & $\alpha_{1}^{(\mathrm{a})}$ & $\left(V_{1} I_{\mathrm{Q}}+C_{\mathrm{eq}} V_{1}^{2} f_{\mathrm{s}}\right) / V_{2}$ \\
\hline$\beta_{i}$ & & $R_{\text {eq,a }} / V_{\text {out }}$ & $\beta_{1}+\left\{\begin{array}{l}\frac{k I_{\mathrm{Q} 0} V_{\text {in }}}{I_{\text {out }} V_{\text {out }}} ; \text { Fig. } 1(\mathrm{a}) \\
\frac{k I_{\mathrm{Q} 0}}{I_{\text {in }}} ; \text { Fig. } 1(\mathrm{~b})\end{array}\right.$ & $R_{\text {eq,a }} / V_{2}$ \\
\hline & $\frac{V_{\text {in }}}{V_{\text {out }}} t_{\mathrm{c}} f_{\mathrm{s}}+$ & $\left\{\begin{array}{l}\frac{I_{\mathrm{Q}} V_{\text {in }}}{I_{\text {out }} V_{\text {out }}}+I_{\text {out }}\left(\frac{R_{\mathrm{Ci}} V_{\text {out }}}{V_{\text {in }}^{2}}+\frac{R_{\mathrm{Co}}}{V_{\text {out }}}\right) ; \text { Fig. } 1(\mathrm{a}) \\
\frac{I_{\mathrm{Q}}}{I_{\text {in }}}+I_{\text {in }}\left(\frac{R_{\mathrm{Ci}}}{V_{\text {in }}}+\frac{R_{\mathrm{Co}} V_{\text {in }}}{V_{\text {out }}^{2}}\right) ; \text { Fig. } 1(\mathrm{~b})\end{array}\right.$ & $\gamma_{1}^{(\mathrm{a})}+\frac{k I_{\mathrm{Q} 0} V_{\text {in }}}{V_{\text {out }}}$ & $\frac{V_{1}}{V_{2}} t_{\mathrm{c}} f_{\mathrm{s}}+\left\{\begin{array}{l}\frac{I_{\mathrm{Q}} V_{1}}{I_{2} V_{2}}+I_{2}\left(\frac{R_{\mathrm{Cl}} V_{2}}{V_{1}^{2}}+\frac{R_{\mathrm{C} 2}}{V_{2}}\right) ;(\mathrm{a}) \&(\mathrm{~d}) \text { Table VI } \\
\frac{I_{\mathrm{Q}}}{I_{1}}+I_{1}\left(\frac{R_{\mathrm{C} 1}}{V_{1}}+\frac{R_{\mathrm{C} 2} V_{1}}{V_{2}^{2}}\right) ;(\mathrm{b}) \&(\mathrm{c}) \text { Table VI }\end{array}\right.$ \\
\hline
\end{tabular}

${ }^{\mathrm{a}}$ But replacing $I_{\mathrm{Q}}$ by $I_{\mathrm{Q} 0}$

TABLE III

VARIABLES AND COMPONENTS WHEN REGULATING THE OUTPUT VOLTAGE

\begin{tabular}{cc}
\hline \hline $\begin{array}{c}\text { Variable or } \\
\text { component }\end{array}$ & Value \\
\hline$V_{\text {in }}$ & $3.5,3.75$, and $4.0 \mathrm{~V}^{(\mathrm{a})}$ provided by Agilent E3631A \\
$V_{\text {out }}$ & $2.2,2.5$, and $2.7 \mathrm{~V}^{(\mathrm{b})}$ set by Agilent E3631A \\
$I_{\text {out }}$ & 5,10, and $20 \mathrm{~mA}$ sunk by Agilent B2901A \\
$L$ & $4.7 \mu \mathrm{H}$, low-ESR \\
$C_{\text {in }}$ & $3 \times 1 \mathrm{mF}$, tantalum, low-ESR \\
$C_{\text {out }}$ & $8 \times 1 \mathrm{mF}^{(\mathrm{c})}$, tantalum, low-ESR \\
$V_{\text {hys }}$ & $10 \mathrm{mV}^{(\mathrm{d})}$ \\
\hline \hline
\end{tabular}

${ }^{a}$ Emulating different states of charge of a single Li-ion battery with a nominal voltage of $3.7 \mathrm{~V}$

${ }^{b}$ Corresponding to different operating voltages of low-power sensor electronics.

${ }^{c}$ This capacitor, together with the selected value of $V_{\text {hys }}$, provided a $t_{\text {active }}$ significantly longer than the $i_{\mathrm{L}}$-regulation transient.

${ }^{\mathrm{d}} \mathrm{A}$ ripple of $20 \mathrm{mV}$ corresponds to less than $1 \%$ of the dc output voltage, which is quite common in commercial converters operating in BM [26].

(1) Characterization of the PV module under irradiancecontrolled laboratory conditions. The PV module was subjected to three irradiance levels (identified as I33, I66, and I100) through a LED array (BXRA-C1202 from Bridgelux) powered at different dc currents and placed at $3 \mathrm{~cm}$ [18]. The levels I33, I66, and I100 approximately correspond to an irradiance of 330,660 , and $1000 \mathrm{~W} / \mathrm{m}^{2}$, respectively, in terms of power generated by the PV module at the MPP. At each irradiance level, the current generated by the PV module was measured at different applied voltages (from $0 \mathrm{~V}$ to $6 \mathrm{~V}$ in steps of $100 \mathrm{mV}$ ) using a source-measurement unit (Agilent B2901).

(2) Evaluation of the efficiency of the buck converter using the $P V$ module. The PV module was connected to the converter instead of the ideal input current source. The efficiency was measured at different values of $I_{\mathrm{L} 0}$ for the three irradiance levels indicated before. At each irradiance level, $V_{\text {in }}$ was set to the MPP voltage found in the characterization so as to extract
TABLE IV

VARIABLES AND COMPONENTS WHEN REGULATING THE INPUT VOLTAGE

\begin{tabular}{cc}
\hline \hline $\begin{array}{c}\text { Variable or } \\
\text { component }\end{array}$ & Value \\
\hline$V_{\text {in }}$ & $3.8,4.0$, and $4.2 \mathrm{~V}^{(\mathrm{a})}$ set by Agilent E3631A \\
$V_{\text {out }}$ & $2.2,2.6$, and $3.0 \mathrm{~V}^{(\mathrm{b})}$ provided by Agilent E3631A ${ }^{(\mathrm{c})}$ \\
$I_{\text {in }}$ & $5.5,11$, and $22 \mathrm{~mA}^{(\mathrm{d})}$ sourced by Agilent B2901A \\
$L$ & $4.7 \mu \mathrm{H}$, low-ESR \\
$C_{\text {in }}$ & $2 \times 1 \mathrm{mF}^{(\mathrm{e})}$, tantalum, low-ESR \\
$C_{\text {out }}$ & $2.2 \mathrm{mF}$, tantalum, low-ESR \\
$V_{\text {hys }}$ & $50 \mathrm{mV}$ \\
\hline \hline
\end{tabular}

${ }^{a}$ Emulating different values of MPP voltage for the SP4.2-37.

${ }^{b}$ Emulating different states of charge of two cylindrical NiMH secondary batteries in series.

${ }^{\mathrm{c}} \mathrm{With}$ a resistor in parallel to operate in the fourth quadrant [27].

${ }^{\mathrm{d}}$ Emulating different values of MPP current for the SP4.2-37.

eThis capacitor, together with the selected value of $V_{\text {hys, }}$ provided a $t_{\text {active }}$ significantly longer than the $i_{\mathrm{L}}$-regulation transient.

the maximum power from the PV module.

\section{EXPERIMENTAL RESULTS}

Experimental waveforms from the circuit in Fig. 4 when regulating the output and input voltage are shown in Figs. 5 and 6, respectively, which are very similar to those represented in Fig. 2. In Fig. 5, the comparator output shows $D_{\mathrm{T}}=9 \%$, which agrees with that predicted by (4), whereas the inductor current has $D=68 \%$, which agrees with that calculated by (1) assuming $\eta \approx 90 \%$ (reported later in Fig. 7). On the other hand, in Fig. 6, the comparator output and the inductor current have $D_{\mathrm{T}}=14 \%$ and $D=76 \%$, which agree with those calculated by (5) and (1), respectively, assuming $\eta \approx 91 \%$ (reported later in Fig. 8).

The experimental results of efficiency versus $I_{\mathrm{L} 0}$ are represented (in points) in Figs. 7 and 8 for the output and input voltage regulation, respectively. In Figs. 7(b) and (c), $\eta$ increases with increasing $V_{\text {out }}$ and $I_{\text {out }}$, as suggested in Section 


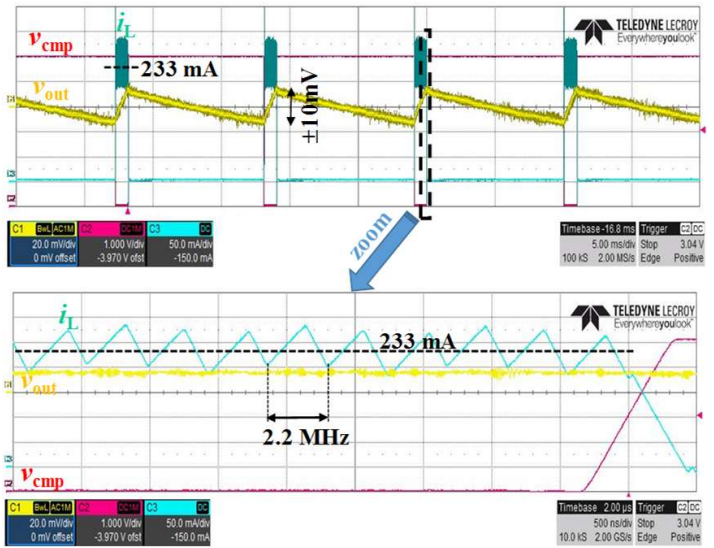

Fig. 5. Experimental waveforms when regulating the output voltage for $V_{\text {in }}=4.0 \mathrm{~V}, V_{\text {out }}=2.5 \mathrm{~V}$, and $I_{\text {out }}=20 \mathrm{~mA}$; channel 1 , which represents $v_{\text {out }}$, is in AC coupling.

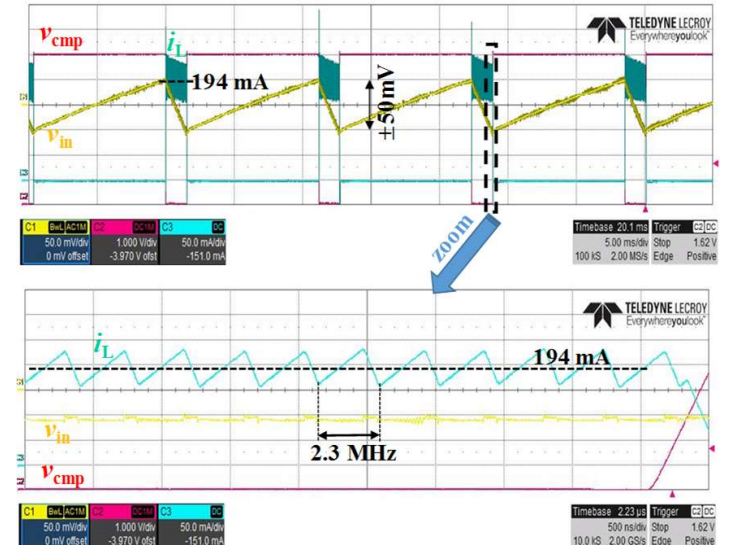

Fig. 6. Experimental waveforms when regulating the input voltage for $V_{\text {in }}=4.2 \mathrm{~V}, V_{\text {out }}=3.0 \mathrm{~V}$, and $I_{\text {in }}=22 \mathrm{~mA}$; channel 1 , which represents $v_{\text {in }}$, is in AC coupling.

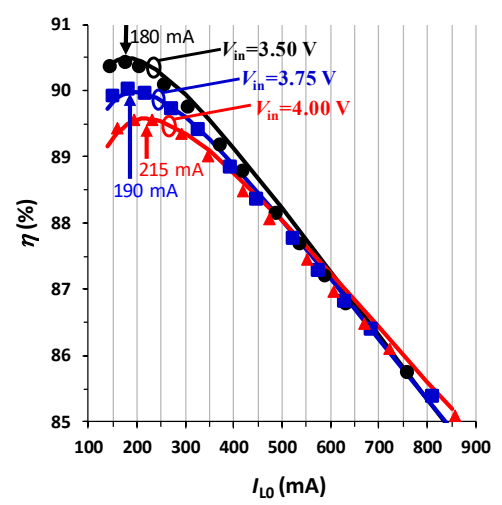

(a)

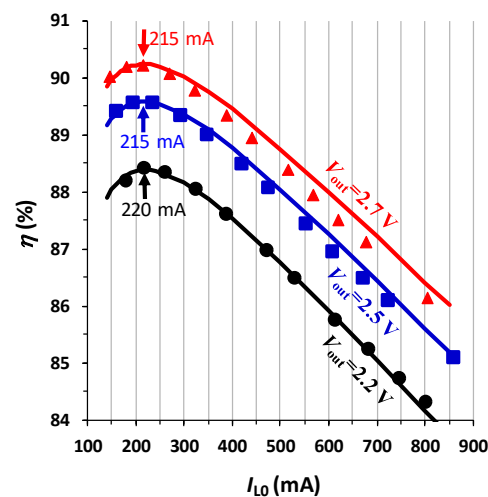

(b)

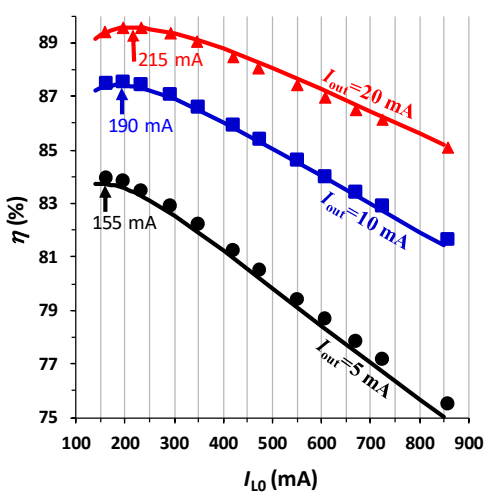

(c)

Fig. 7. Experimental (points) and predicted (line) efficiency versus $I_{\mathrm{L} 0}$ when regulating the output voltage for different values of (a) $V_{\text {in }}$, (b) $V_{\text {out }}$, and (c) $I_{\text {out }}$. The default values are $V_{\text {in }}=4.0 \mathrm{~V}, V_{\text {out }}=2.5 \mathrm{~V}$, and $I_{\text {out }}=20 \mathrm{~mA}$

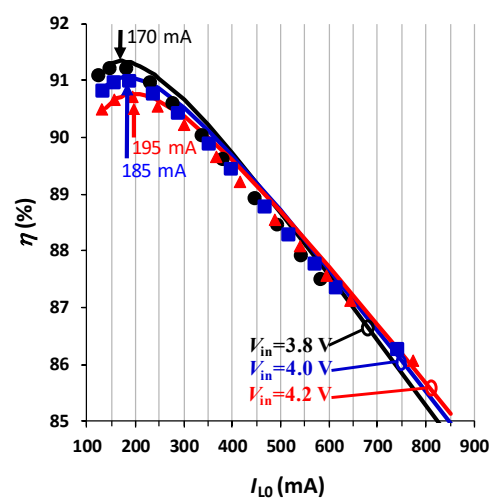

(a)

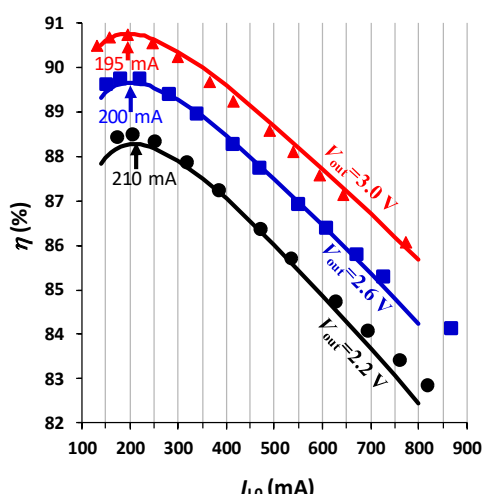

(b)

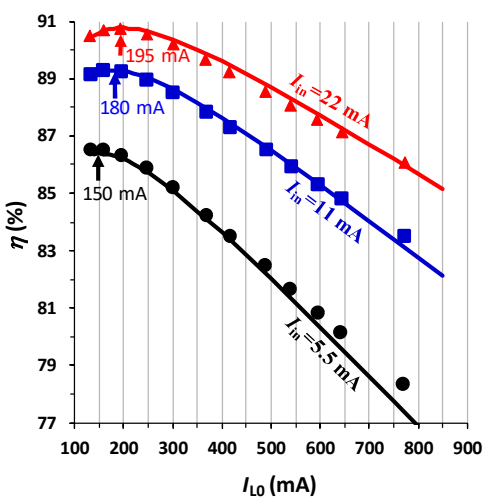

(c)

Fig. 8. Experimental (points) and predicted (line) efficiency versus $I_{\mathrm{L} 0}$ when regulating the input voltage for different values of (a) $V_{\text {in }}$, (b) $V_{\text {out }}$, and (c) $I_{\text {in. }}$. The default values are $V_{\text {in }}=4.2 \mathrm{~V}, V_{\text {out }}=3.0 \mathrm{~V}$, and $I_{\text {in }}=22 \mathrm{~mA}$.

III. In Fig. 7(a), $\eta$ tends to increase with decreasing $V_{\text {in }}$ although the change is not as high as in Figs. 7(b) and (c). Moreover, $I_{\mathrm{L} 0 \text {,opt }}$ increases with increasing $V_{\text {in }}$ and $I_{\text {out }}$, but it is quite independent of $V_{\text {out, }}$ as predicted by (9). Such dependencies are also applicable in Fig. 8 but with two differences: 1) the effects of $I_{\text {out }}$ must be replaced by those of $I_{\text {in }}$, and 2) $I_{\mathrm{L} 0 \text {,opt }}$ also increases with decreasing $V_{\text {out }}$. Figs. 7 and
8 show an efficiency increase up to $9 \%$ when $I_{\mathrm{L} 0 \text {,opt }}$ is applied. This is using as a reference the efficiency obtained at the maximum value of $I_{\mathrm{L} 0}$ (i.e. $800-900 \mathrm{~mA}$ ), which involves the fastest, but not the optimal, energy transfer.

Figs. 7 and 8 also show, through a continuous line, the efficiency predicted by the model proposed in Section III.B using the data specified in Table V. Theoretical and 
(a)

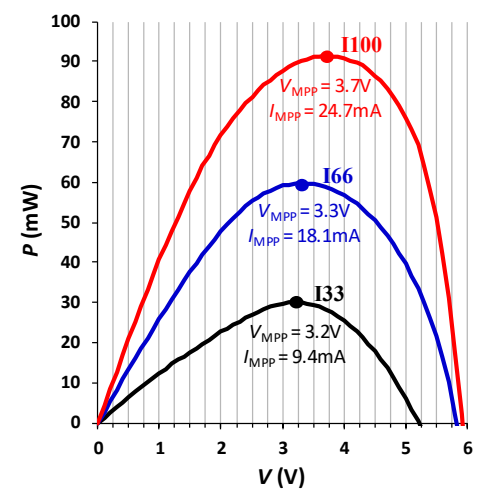

(b)

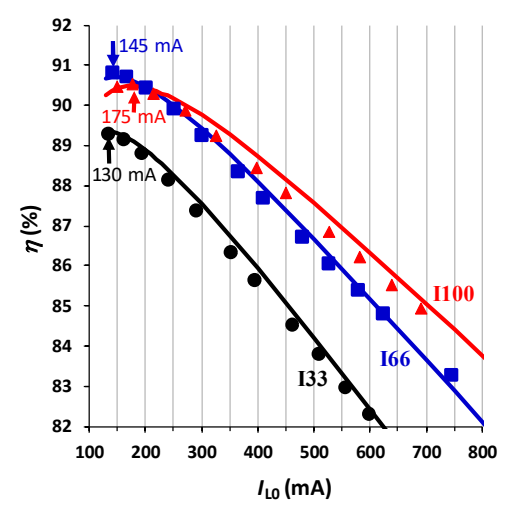

Fig. 9. (a) Experimental power-voltage curves of the PV module under test for different irradiance levels. (b) Experimental (points) and predicted (line) efficiency of the converter versus $I_{\mathrm{L} 0}$ for different irradiance levels.

experimental results show an excellent agreement, with discrepancies smaller than $0.5 \%$. The model proposed in Section III.A was not able to predict the experimental performance. For example, the experimental results in Fig. 7(c) show, at medium-high values of $I_{\mathrm{L} 0}$, a slope that decreases (in absolute value) with increasing $I_{\text {out, }}$, which is not predicted by $\beta_{1}$, but it does by $\beta_{2}$.

The power-voltage curves of the PV module are represented in Fig. 9(a) for the three irradiance levels. The power, current $\left(I_{\mathrm{MPP}}\right)$, and voltage $\left(V_{\mathrm{MPP}}\right)$ at the MPP increased with increasing the irradiance level, as expected at room temperature. In comparison with the reported typical values $(22 \mathrm{~mA} / 4.2 \mathrm{~V})$ at STC, the module under test provided a higher current and a lower voltage. The differences were around $10 \%$ and can be ascribed to both manufacturing tolerances and thermal effects. Fig. 9(b) shows the experimental (points) and predicted (line) efficiency of the converter versus $I_{\mathrm{L} 0}$ when the PV module was connected to its input, assuming $V_{\text {out }}=2.4 \mathrm{~V}$. Three main conclusions can be drawn. First, the agreement between the experimental and predicted values is again remarkable. Second, an irradiance increase does not involve unavoidably an efficiency increase, as happens in a boost converter [19]. This is because the higher the irradiance, the higher both $V_{\text {MPP }}$ and $I_{\text {MPP }}$ [and, hence, $V_{\text {in }}$ and $I_{\text {in }}$ in Fig. 1(b)], which involves opposite effects in terms of efficiency, as shown before separately in Figs. 8(a) and $8(\mathrm{c})$. And third, $I_{\mathrm{L} 0 \text {,opt }}$ increases with increasing the irradiance, which is predicted by (9) considering that both $V_{\text {in }}$ and $I_{\text {in }}$ increase with increasing the irradiance. The same
TABLE V

NUMERICAL VALUES OF THE VARIABLES INVOLVED IN THE POWER LOSSES

\begin{tabular}{lcc}
\hline \hline \multicolumn{1}{c}{ Variable } & Regulating $\boldsymbol{V}_{\text {out }}$ & Regulating $\boldsymbol{V}_{\text {in }}$ \\
\hline$R_{\mathrm{Ci}}{ }^{(\mathrm{a})}(\mathrm{m} \Omega)$ & 10 & 15 \\
$R_{\mathrm{P}^{(\mathrm{b})}}(\mathrm{m} \Omega)$ & 130 & 130 \\
$R_{\mathrm{N}}{ }^{(\mathrm{b})}(\mathrm{m} \Omega)$ & 58 & 58 \\
$R_{\mathrm{L}}{ }^{(\mathrm{a})}(\mathrm{m} \Omega)$ & 52 & 52 \\
$R_{\mathrm{Co}}{ }^{(\mathrm{a})}(\mathrm{m} \Omega)$ & 4 & 55 \\
$C_{\mathrm{eq}}{ }^{(\mathrm{c})}(\mathrm{pF})$ & 375 & 300 \\
$t_{\mathrm{c}}{ }^{(\mathrm{c})}(\mathrm{ns})$ & 12 & 12 \\
$I_{\mathrm{Q} 0}{ }^{(\mathrm{d})}(\mu \mathrm{A})$ & 240 & 236 \\
$k^{(\mathrm{d})}\left(\mathrm{A}^{-1}\right)$ & 2.167 & 2.180 \\
\hline \hline
\end{tabular}

${ }^{a}$ Typical value from the datasheet.

${ }^{\text {b}}$ Typical value at $V_{\text {in }}=5 \mathrm{~V}$ from the datasheet. This resistance, however, was assumed to be dependent on $V_{\text {in }}$.

'These values were extracted by fitting (8) with $i=2$ to a single set of experimental data.

${ }^{\mathrm{d}}$ Measured values.

experiment for a boost converter showed a constant value of $I_{\mathrm{L} 0 \text {,opt }}[19]$, but this is because its $I_{\mathrm{Q}}$ was almost independent of $I_{\mathrm{L} 0}$, otherwise $I_{\mathrm{L} 0 \text {,opt }}$ would also depend on the irradiance.

\section{DISCUSSION}

A buck converter regulating the output voltage is equivalent to a boost converter regulating the input voltage, although the energy goes in opposite directions. Analytically, the expressions of $\eta$ and $I_{\mathrm{L} 0 \text {,opt }}$ obtained here are equal to those derived in [19] if $V_{\text {in }}, V_{\text {out }}$, and $I_{\text {out }}$ are replaced by $V_{\text {out }}, V_{\text {in }}$, and $I_{\text {in, }}$ respectively. A similar situation occurs when a buck converter regulating the input voltage is compared with a boost converter regulating the output voltage. These four cases (buck/boost, output/input regulation) are proposed to be analyzed through a more general approach using the equivalent circuits shown in Table VI, where only the independent input/output variables are shown in each case. In these circuits, the left (right) side is identified as port 1 (2) and their variables have the subscript 1 (2). Port 1 is the input and port 2 is the output in a buck converter, but they swap their roles in a boost converter. Assuming these circuits and the basic model in Section III.A, the four cases can be uniformly modeled as follows. On the one hand, $\eta$ can be expressed by (8) assuming the coefficients with $i=3$ in Table II, where $R_{\mathrm{C} 1}$ and $R_{\mathrm{C} 2}$ are, respectively, the parasitic series resistance of $C_{1}$ and $C_{2}$, and $R_{\text {eq,a }}$ is

$$
R_{\text {eq,a }}=\left(R_{\mathrm{C} 1}+R_{\mathrm{P}}\right) \frac{V_{2}}{V_{1}}+R_{\mathrm{N}}\left(1-\frac{V_{2}}{V_{1}}\right)+R_{\mathrm{L}}+R_{\mathrm{C} 2}
$$

On the other hand, $I_{\mathrm{L} 0 \text {,opt }}$ can be written as

$$
I_{\mathrm{L} 0, \mathrm{opt}}=\sqrt{\frac{V_{1} I_{\mathrm{Q}}+C_{\mathrm{eq}} V_{1}^{2} f_{\mathrm{s}}}{R_{\mathrm{eq}, \mathrm{a}}}}
$$

which depends on $V_{\text {in }}$ in a buck converter, but on $V_{\text {out }}$ in a boost converter.

Some design parameters involved in (9) can either be 
TABLE VI

EQUIVALENT CIRCUITS FOR THE FOUR CASES (BUCK/BOOST, OUTPUT/INPUT REGULATION) UNDER STUDY

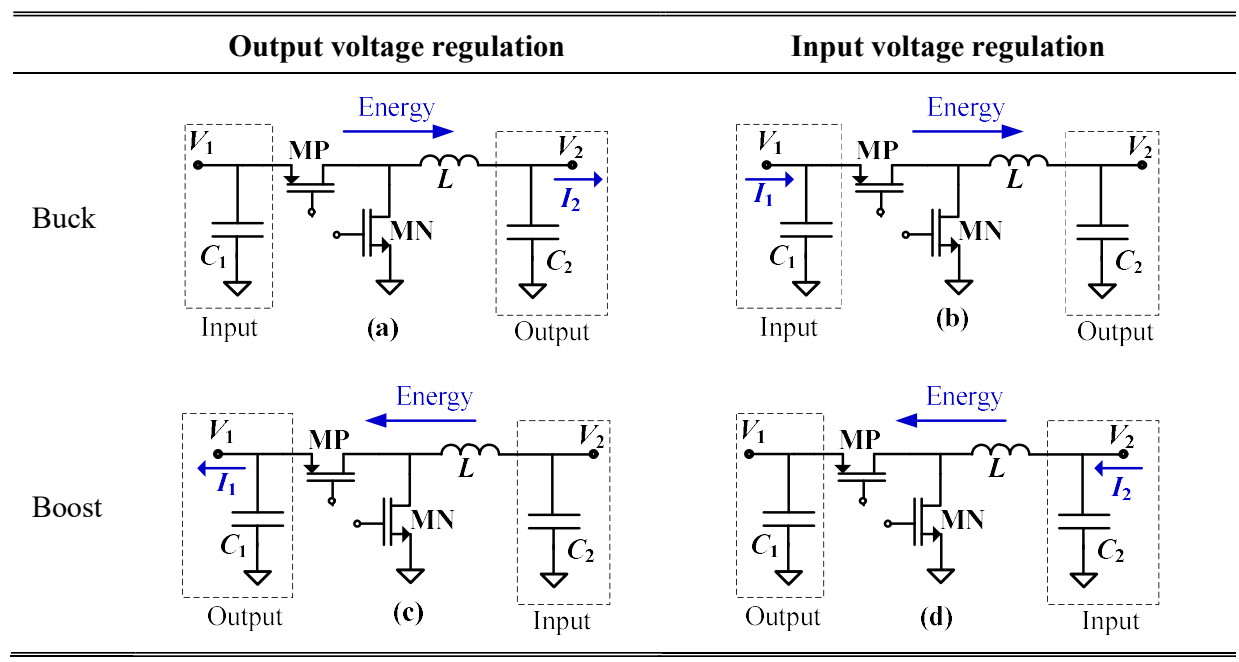

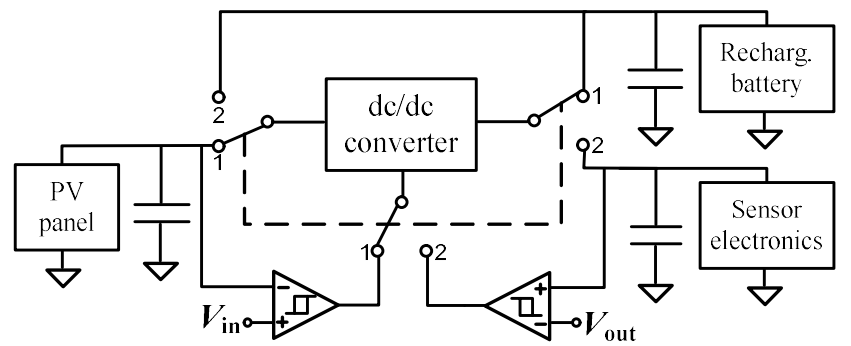

Fig. 10. Reconfigurable topology based on a single dc/dc converter for the regulation of both input and output voltage.

unavailable or vary from their nominal value. Therefore, in a practical implementation, $I_{\mathrm{L} 0 \text { opt }}$ is expected to be automatically tracked through a control algorithm, such as the perturb and observe method [18], causing a power overhead significantly lower than the power improvement generated by the fact of

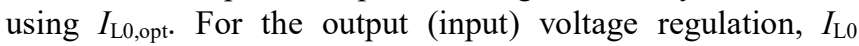
would be slightly perturbed and the input (output) power observed, assuming the output (input) power constant during the control cycle. If the input (output) power decreases (increases), the perturbation should be kept in the same direction; otherwise, it should be reversed. For the TPS62750, $I_{\mathrm{L} 0}$ could be perturbed using a digital potentiometer instead of $R_{\text {LIM }}$ in Fig. 4 . The input (output) power could be observed by sensing, for example, the increment of voltage across a small input (output) capacitor connected in parallel with the main storage device that would be disconnected for a short and known time interval [28]. For the case studied in Fig. 9, we estimate that the tracking power overhead should be lower than $100 \mu \mathrm{W}$, which seems feasible considering that values of units or tens of $\mu \mathrm{W}$ have been recently reported [15]. This power overhead could also be improved if the different variables to be optimized (i.e. $V_{\text {in }}$ and $I_{\mathrm{L} 0}$ ) in Fig. 1(b) were holistically tracked, and not independently.

Taking into account that the dc/dc converters in Figs. 1(a) and 1 (b) remain inactive most of the time, a single converter could be multiplexed to carry out both voltage regulations. A proposal of this reconfigurable topology is shown in Fig. 10, where the converter regulates the input voltage when the three single-pole double-throw switches are at position 1 , and the output voltage when they are at position 2 . The main advantage of this topology is that many components are shared and, hence, the design is in principle more compact. The main drawbacks are the increase of conduction losses generated by the on-resistance of the switches, and the complexity of the control algorithm deciding which regulation must be carried out. A more complete analysis of such a topology will be presented in future works.

\section{CONCLUSION}

A theoretical analysis and a set of experimental results have demonstrated that buck $\mathrm{dc} / \mathrm{dc}$ converters operating in BM have, in terms of efficiency, an optimal inductor current to transfer the energy from the input to the output during the burst. Such results are applicable to buck converters regulating its output voltage, which corresponds to the supply voltage of a low-power sensor node, as well as those regulating its input voltage, which corresponds to the operating voltage of a lowpower energy transducer. Both scenarios have been theoretically analyzed and then experimentally proved using a commercial buck dc/dc converter. Experimental tests have shown that the use of this optimal inductor current, which is around $200 \mathrm{~mA}$ for the operating conditions under test, provides up to $9 \%$ increase in efficiency. Additional experiments regulating the operating voltage of a low-power PV module have shown that the effects of irradiance on both the efficiency and the optimal inductor current of a buck converter are different than those found in the literature for a boost converter. Furthermore, a general approach has been provided to uniformly tackling the performance of buck and boost converters operating in BM.

\section{ACKNOWLEDGMENT}

The authors would like to thank Dr. Oscar Lopez and the UPC technical services for providing the light-source setup. 


\section{REFERENCES}

[1] I. Jauregi, H. Solar, A. Beriain, I. Zalbide, A. Jimenez, I. Galarraga, and R. Berenguer, "UHF RFID temperature sensor assisted with body-heat dissipation energy harvesting," IEEE Sens. J., vol. 17, no. 5, pp. 14711478, Mar. 2017.

[2] J.-J. Chen, Y.-S. Hwang, J.-H. Yu, Y.-T. Ku, and C.-C. Yu, "A low-EMI buck converter suitable for wireless sensor networks with spur-reduction techniques," IEEE Sens. J., vol. 16, no. 8, pp. 2588-2597, Apr. 2016.

[3] Y.-S. Hwang, J.-J. Chen, B.-H. Lai, Y.-T. Ku, and C.-C. Yu, "A fasttransient boost converter with noise-reduction techniques for wireless sensor networks," IEEE Sens. J., vol. 16, no. 9, pp. 3188-3197, May 2016.

[4] J.-C. Tsai, T.-Y. Huang, W.-W. Lai, and K.-H. Chen, "Dual modulation technique for high efficiency in high-switching buck converters over a wide load range," IEEE Trans. Circuits Syst. I, Reg. Papers, vol. 58, no. 7, pp. 1671-1680, Jul. 2011.

[5] W. Fu, S. Tong Tan, M. Radhakrishnan, R. Byrd, and A. A. Fayed, "A DCM-only buck regulator with hysteretic-assisted adaptive minimumon-time control for low-power microcontrollers," IEEE Trans. Power Electron., vol. 31, no. 1, pp. 418-429, Jan. 2016.

[6] S. K. Kok, M. Mao, and X. Gong, "Burst-mode operation of a switching converter," U.S. 2012/0250378 A1 patent, Oct. 4, 2012.

[7] F. Reverter and M. Gasulla, "Optimal inductor current in boost DC/DC converters operating in burst mode under light-load conditions," IEEE Trans. Power Electron., vol. 31, no. 1, pp. 15-20, Jan. 2016.

[8] P. Liu, W. Ye, J. Tai, H. Chen, J. Chen and Y. Chen, "A high-efficiency CMOS DC-DC converter with 9- $\mu$ s transient recovery time," IEEE Trans. Circuits Syst. I, Reg. Papers, vol. 59, no. 3, pp. 575-583, Mar 2012.

[9] J.-W. Ha, B.-H. Park, and J.-H. Chun, "A 7-MHz integrated peakcurrent-mode buck regulator with a charge-recycling technique," IEEE Trans. Circuits Syst. II, Exp. Briefs, vol. 64, no. 7, pp. 797-801, Jul. 2017.

[10] P. Malcovati, M. Belloni, F. Gozzini, C. Bazzani, and A. Baschirotto, "A 0.18- $\mu \mathrm{m}$ CMOS, 91\%-efficiency, 2-A scalable buck-boost DC-DC converter for LED drivers," IEEE Trans. Power Electron., vol. 29, no. 10, pp. 5392-5398, Oct. 2014

[11] V. Michal, "Peak-efficiency detection and peak-efficiency tracking algorithm for switched-mode DC-DC power converters," IEEE Trans. Power Electron., vol. 29, no. 12, pp. 6555-6568, Dec. 2014.

[12] S. Zhou and G.A. Rincón-Mora, "A high efficiency, soft switching DCDC converter with adaptive current-ripple control for portable applications," IEEE Trans. Circuits Syst. II, Exp. Briefs, vol. 53, no. 4, pp. 319-323, April 2006.

[13] J.-M. Wang and S.-T. Wu, "A synchronous buck dc-dc converter using a novel dual-mode control scheme to improve efficiency," IEEE Trans. Power Electron., vol. 32, no. 9, pp. 6983-6993, Sep. 2017.

[14] T. Ruan, Z. J. Chew, and M. Zhu, "Energy-aware approaches for energy harvesting powered wireless sensor nodes," IEEE Sens. J., vol. 17, no. 7, pp. 2165-2173, Apr. 2017.

[15] K. Rawy, F. Kalathiparambil, D. Maurath, and T. T.-H. Kim, "A selfadaptive time-based MPPT with $96.2 \%$ tracking efficiency and a wide tracking range of $10 \mu \mathrm{A}$ to $1 \mathrm{~mA}$ for IoT applications," IEEE Trans. Circuits Syst. I, Reg. Papers, vol. 64, no. 9, pp. 2334-2345, Sep. 2017.

[16] F. I. Simjee and P. H. Chou, "Efficient charging of supercapacitors for extended lifetime of wireless sensor nodes," IEEE Trans. Power Electron., vol. 23, no. 3, pp. 1526-1536, May 2008.

[17] C. Alippi and C. Galperti, "An adaptive system for optimal solar energy harvesting in wireless sensor network nodes," IEEE Trans. Circuits Syst. I, Reg. Papers, vol. 55, no. 6, pp. 1742-1750, July 2008.

[18] O. Lopez-Lapeña, M. T. Penella, and M. Gasulla, "A closed-loop maximum power point tracker for subwatt photovoltaic panels," IEEE Trans. Ind. Electron., vol. 59, no. 3, pp. 1588-1596, March 2012.

[19] F. Reverter and M. Gasulla, "Optimal inductor current in boost DC/DC converters regulating the input voltage applied to low-power photovoltaic modules," IEEE Trans. Power Electron., vol.32, no. 8, pp. 6188-6196, Aug. 2017.

[20] T. Becker, M. Kluge, J. Schalk, K. Tiplady, C. Paget, U. Hilleringmann, and T. Otterpohl, "Autonomous sensor nodes for aircraft structural health monitoring," IEEE Sens. J., vol. 9, no. 11, pp. 1589-1595, Nov. 2009.

[21] R. Erickson and D. Maksimovic, "High efficiency DC-DC converters for battery-operated systems with energy management," Worldwide Wireless Commun., (Annu. Rev. Telecommun.), pp. 1-10, 1995.
[22] D. Cesarini, V. Jelicic, M. Kuri, M. Marinoni, D. Brunelli, and V. Bilas, "Experimental validation of energy harvesting-system availability improvement through battery heating," IEEE Sens. J., vol. 17, no. 11, pp. 3497-3506, Jun. 2017.

[23] M.K. Kazimierczuk, Pulse-Width Modulated DC-DC Power Converters. Chichester, UK: Wiley, 2008.

[24] A. Raj, "Calculating efficiency," Texas Instruments, Dallas, TX, USA, Rep. SLVA390, 2010.

[25] Texas Instruments, "High efficiency step-down converter for USB applications," TPS62750 datasheet, July 2009 (Revised Sep. 2009).

[26] Linear Technology, "Micropower high efficiency DC/DC converters with low-battery detector adjustable and fixed 5V," LT1303 datasheet, 1995.

[27] F. Reverter and M. Gasulla, "Improving the efficiency of PV low-power processing circuits by selecting an optimal inductor current of the DC/DC converter," in Proc. Eurosensors XXVIII, 2014, pp. 1214-1217.

[28] P. Proynov, G. D. Szarka, N. Mcneill, and B. H. Stark, "Switchedcapacitor power sensing in low-power energy harvesting systems," Electron. Lett., vol. 49, no. 2, pp. 151-152, Jan. 2013.

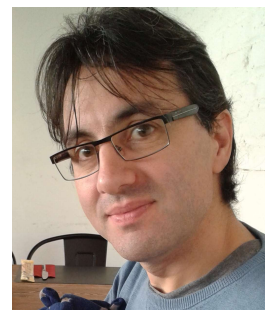

Ferran Reverter was born in Llagostera, Spain, in 1976. He received the B.Sc. degree in industrial electronic engineering from the University of Girona, Girona, Spain, in 1998, the M.Sc. degree in electronic engineering from the University of Barcelona, Barcelona, Spain, in 2001, and the Ph.D. degree in electronic engineering from the Universitat Politècnica de Catalunya (UPC), Barcelona, Spain, in 2004

Since 2001, he has been with the UPC, where he is an Associate Professor in Analog Electronics and Digital Systems. Since 2018, he has also been with the Open University of Catalonia, where he is a Course Instructor in Electronic Instrumentation. He was a visiting PostDoctoral Researcher with the Delft University of Technology, Delft, The Netherlands from 2005 to 2007, and with the Imperial College London, London, U.K., in 2012. His current research interests include interface electronics based on microcontrollers for smart sensors, power-processing circuits based on $\mathrm{dc} / \mathrm{dc}$ converters for autonomous sensors, and temperature sensors based on MOSFETs for on-chip thermal testing of ICs.

He was awarded "Outstanding Reviewer" from the IEEE Instrumentation and Measurement Society in 2014. He is an Associate Editor of the IEEE SENSORS JOURNAL and IEEE TRANSACTIONS ON INSTRUMENTATION AND MEASUREMENT.

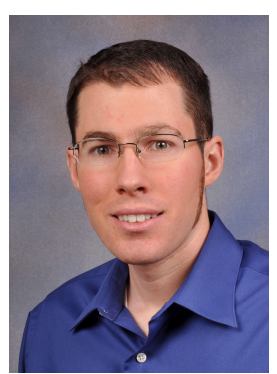

Chris Glaser received the bachelor degree in electrical engineering from Texas A\&M in College Station, Texas. $\mathrm{He}$ is a Senior Applications Engineer and Member, Group Technical Staff for Texas Instruments (TI) Low Power DC/DC group. In this role, he supports customers, designs evaluation modules (EVMs), writes application notes, trains field engineers and customers, and generates technical collateral to make TI parts easier to use.

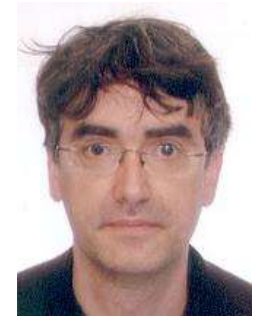

Manel Gasulla was born in Vinaròs, Spain, on May 26, 1967. He received the Enginyer (MEng) and Doctor Enginyer (PhD) degrees in Telecommunications from the Universitat Politècnica de Catalunya (UPC), Barcelona, in 1992 and 1999, respectively.

Since 1993 he has been with the UPC, where he is an associate professor, engaged in teaching on Analog and Power Electronics and Electronic Instrumentation. In 2001-2002 he was a Visiting Postdoctoral Fellow at the Electronic Instrumentation Laboratory, Delft University of Technology, The Netherlands. His research interests include capacitive sensors, direct sensor-to-microcontroller interfaces, and energy harvesting and wireless power transfer circuits for autonomous sensors. He is co-author of more than 50 papers in journals and conferences, six Spanish patents, several chapters in books and the book Powering Autonomous Sensors (Springer, 2011). 